\title{
AOR
}

Selected Papers of \#AolR2021:

The 22nd Annual Conference of the

Association of Internet Researchers

Virtual Event / 13-16 Oct 2021

\section{THE QUANTUM STATE OF INFRASTRUCTURE RECONFIGURATION IN 5G}

\author{
Niels ten Oever \\ University of Amsterdam
}

Transnational information networks are a proxy for power that embody visions of futures and possibilities (Mosco 2005; DeNardis 2020). This paper looks at the topological reconfiguration of networks that comes with the development and deployment of $5 \mathrm{G}$ technologies. The paper argues that $5 \mathrm{G}$ networks exist in an apparent paradox of quantum superposition: the networks are controlled both by states and private corporations, and the intelligence is located both in the end-points as well as in the network. But just like in the thought experiment of Schrödinger's cat, if one would observe the networks in case of an incident, the control over the network resides inside the network and with the state. However, this would merely describe the topographic qualities of the network, not its topological configuration.

I use the concept of a quantum state that originates in physics, but is readily used in quantum social science (ie Barad 2007; Der Derian and Wendt 2020), to explain how, in the development of the topology of $5 G$ networks, several 'states' that seem exclusionary occur simultaneously. This approach helps to explore how the creation of material possibilities in transnational information networks is entangled with transnational institutions, markets, and nation-states. Through this contribution, I seek to build a bridge between constructivist and realist traditions in international relations by using approaches from quantum social science and science and technology studies to increase understanding of the role of communication networks in tussles for power.

\section{Methods}

For this paper, I engaged in code ethnography of open source $5 \mathrm{G}$ implementations through the deployment of experimental telecommunications networks. Next to that, I engaged in statistical, discourse, and network analysis of $5 G$ standards and mailinglist conversations and participant observation in the main standards body that is responsible for the development of 5G, the Third Generation Protocol Partnership (3GPP). The combination of these methods allows me to gain insights into the workings of $5 G$ infrastructure production, and the motives, interests, and approaches of the engaged stakeholders.

Suggested Citation (APA): ten Oever, N. (2021, October). The Quantum State of Infrastructure Reconfiguration in 5G. Paper presented at AolR 2021: The 22nd Annual Conference of the Association of Internet Researchers. Virtual Event: AolR. Retrieved from http://spir.aoir.org. 


\section{State - Capital | Center - Edge}

Historically, the development of transnational communication networks are analyzed along two axes: the axis of public or private control, and the axis where control over data streams is situated: either inside or at the edges of the network (Zajácz 2019). For example, the working of telegraph networks depended on extensive encoding, decoding, and routing in the network by operators, therefore the intelligence and control were located in the network. Telegraph networks in the United States were owned by private capital, whereas in Europe these networks were controlled by states (Richardson 2015). The early internet in the United States was financed by the state, but the design of the network was such that control of the network resides at the edges (Russell 2014). With the commercialization and privatization of the internet in the 1990s, the ownership of the internet came under the control of private corporations, but the design did not change. The distributed transnational design of the internet has on the one hand allowed companies to leverage network externalities and on the other hand complicated it for countries to develop regulations. This has led to a call for regulation that has thus far been hard to implement because of the distributed nature of the Internet. 5G might be an old solution to this relatively new problem: to put more control in the network and increase the influence of the state.

\section{New Frequencies and New Hardware}

Like its predecessors $3 G$ and $4 G, 5 G$ is developed in the telecom industry's largest standards initiative: the 3rd Generation Partnership Project (3GPP) and then subsequently standardized by the oldest still function international organization: the International Telecommunications Union (ITU). The ITU was established in 1865 to standardize and facilitate telegraph communication among nation-states, and that is what it still does. The main changes coming about with the deployment of $5 \mathrm{G}$ are driven by the use of new frequencies to transmit data $(2.5-3.7 \mathrm{GHz}$ with a 100-900 Mbit/s throughput and 25-39 GHz with an expected throughput of several Gbit/s). The usage of higher frequencies means that waves carry less far and new antennas and routers need to be placed in public space. The deployment of new hardware brings about new information architecture designs. The increase in processor speeds and the drop in the cost of memory allows for many functions not to be implemented in hardware, as was traditionally the case, but as software. Whole telecommunications infrastructure networks will be remotely configurable, continuously updated, and algorithmically optimized. This expands the role of the network beyond the mere data carrier it used to be: computing is now located in the network. The network becomes a data server and computer, the city becomes a data center.

\section{A Smart Network for Intelligence}

The introduction of technical concepts such as Software Defined Networking, Network Function Virtualization, and Edge Computing in the standards documents of $5 \mathrm{G}$ are technical descriptions for the move away from a 'dumb network' that solely serves as data transport between servers, to an intelligent network. Previous intelligent networks used to have 'dumb endpoints', think for instance the telephones with a dial. Current mobile phones, laptops, tablets, and other devices are often more powerful than supercomputers from the 1990s, these can hardly be described as dumb. However, there is an increase in devices that are mostly used as sensors, more commonly known as the Internet of Things. These devices can be directly linked to the network through 
the use of software-based embedded SIM cards. At the same time, Content Distribution Networks provide much-requested content, such as video and podcasts, from inside access networks instead from the other side of the globe. While a user in Europe visits a Netflix website that is expected to be in the United States, the video content is served from a server nearby. The network does not only knows more about users, it stores data according to expected behavior, proximity, and device profiles - and according to local norms.

\section{Anticipation and Probability}

$5 G$ networks are not optimized for anything - they are optimized for everything. The Internet has grown, independent Internet Service Providers have almost all been bought up by telecommunication providers that more often than not have their roots in state monopolies or their heirs. 5G technologies reintroduce heterogeneous networks in a consolidated media environment where both nation-states and transnational corporations would like to have more insight and control over data streams. Telecommunication providers have now placed themselves in-between states and corporate content providers, with a network that can serve both with the fastest connection, the lowest latency, and the most specific geolocation data. They provide a network that is a platform for cognition. In the deployment and operation of 5G networks, technology is closely entangled with discourse, the economical, and the political - jointly they form the social and the subjective. The state has power over topographical networks because the computation will be local and the institutional reality of the interrelation between state and telecom corporations and their regulatory history. At the same time, the state has no capacity to understand the topological vastness of the algorithmic complexity of software defined $5 \mathrm{G}$ networks. The co-existential limbo of vendors, operators, and so-called verticals in the 3GPP on the one hand and the states in the ITU on the other shows the interrelation and entanglement between these actors. The increasing provision of public services through information networks increased the state's dependence on them, together with the increase in the production of personal data of citizens and sensitive data on corporations demanded for increased control and guarantees by the state. The lack of jurisdictional authority has led states to develop their own data governance regimes, which added intelligence to the network. But the draw of network externalities that come with low barrier exchange of information and services across borders is what keeps networks open.

To understand $5 G$ networks and their development one should not seek to describe or validate whether control over data-streams is located in the networks or at the edges, or whether the networks are controlled by the state or corporations, simply because they are all true at the same time.

Barad, Karen. 2007. Meeting the Universe Halfway: Quantum Physics and the Entanglement of Matter and Meaning. Duke University Press Books.

DeNardis, Laura. 2020. The Internet in Everything: Freedom and Security in a World with No off Switch. Yale University Press.

Der Derian, James, and Alexander Wendt. 2020. “'Quantizing International Relations': The Case for Quantum Approaches to International Theory and Security Practice." Security Dialogue 51 (5): 399-413. 
Mosco, Vincent. 2005. The Digital Sublime: Myth, Power, and Cyberspace. The MIT Press.

Richardson, Alan J. 2015. "The Cost of a Telegram: Accounting and the Evolution of International Regulation of the Telegraph." Accounting History 20 (4): 405-29.

Russell, Andrew L. 2014. Open Standards and the Digital Age. Cambridge University Press.

Zajácz, Rita. 2019. Reluctant Power: Networks, Corporations, and the Struggle for Global Governance in the Early 20th Century. MIT Press. 